\title{
OXIDATIVE STABILITY OF SEVERAL FISHERY PRODUCTS DURING PROCESSING AND STORAGE
}

\author{
Hari Eko (rianto*), Jovita Tri Murtini*) and Suparno*)
}

\begin{abstract}
Investigation on oxidative stability of several fishery products during processing and storage was carried out in Pekalongan and Muncar during the period of 1994-1995. Fishery products used in the study were dried salted mackerel, boiled salted sardine, spongy fermented fish and canned sardine. Raw materials and their products were purchased from the processors. The processing procedures were investigated by observing their activities. Results showed that drying, salting, boiling and canning have induced reduction of omega- 3 fatty acid due to oxidation. High reduction was found in the processing of dried salted fish, boiled salted fish and canned fish. Further reduction was also noted during storage, particularly in dried salted fish, boiled salted fish and spongy fermented fish.
\end{abstract}

KEYWORD: oxidative stability, processing, storage, fishery products

\section{INTRODUCTION}

Total catch of Indonesian marine fishes in 1996 was $3,383,457$ ton and nearly $47 \%$ of the catch was converted into several types of processed products, such as dried salted fish, boiled salted fish, fermented fish and canned fish (Directorate General of Fisheries, 1998). This information indicates that processed products play an important role in providing fish to Indonesian consumers

Processing and storage induce changes in the properties of the product. Processing, involving heating, will accelerate oxidation process in the product, especially if the processing conducted without any protection. Oxidation is suspected as the main cause of lipid deterioration in fish. Fish lipids are the most polyunsaturated fatty acids compared to other lipids or oils. Thus fish lipids are very susceptible to oxidation reaction. Autoxidation is commonly suspected as the main chemical process in reducing fish lipid quality. The principle sites of attack by oxygen during oxidation process are unsaturated portions of the fatty acids within triglycerides, especially polyunsaturated fatty acids with five and six double bonds, such as eicosapentaenoic acid (EPA) and docosahexaenoic acid (DHA).

Changes in the product during storage is not only chemically, but also enzymatically, microbiologically and organoleptically. Those changes induce product deterioration which finally causes product rejection by consumer due to spoilage. The main indication of product deterioration is by arising undesirable organoleptic properties.

In this study, oxidative stability of several fishery products during processing and storage were investigated. The processed products selected for the study were dried salted fish, boiled salted fish, spongy fermented fish and canned fish.

\section{MATERIAL AND METHODS}

During sample collection, raw materials and their products were purchased from the processors in Pekalongan and Muncar during the period of 1994-1995. Each type of products was obtained from two processors. The processing procedures were investigated by observing their activities.

\section{Sample Collection and Processing Methods}

\section{Dried salted short-bodied mackerel}

Dried salted short-bodied mackerel and its raw material were purchased from two processors in Pekalongan, Central Java. Short-bodied mackerel bought by dried salted fish processors was already salted on board. To produce dried salted fish, the fish was soaked in clean water for 15 minutes and then sun dried for two days.

Proximate composition of raw material used was $67.36 \%$ moisture, $22.50 \%$ protein, $0.81 \%$ fat and $8.74 \%$ ash.

\footnotetext{
'Researcher of Slipi Resenrch station for Marine Fisheries
} 


\section{Spongy fermented fish (Jambal Roti)}

Spongy fermented fish and its raw material were obtained from processors in Pekalongan, Central Java. Marine catfish was used for raw material of spongy fermented fish product and the processing method applied to produce that product was as follows:

Fish was washed before beheaded and gutted.

- Clean fish was allowed to undergo autolysis process at ambient temperature for 24 hours.

- This process is normally called with "pembengkakan", swelling process.

- Autolyzed fish was washed and then salted using mixed salting method for 24 hours.

- After that, the fish was washed to remove remaining salt on the surface of fish and the fish was subsequently split into butterfly form.

- The split fish was sun dried for a day and then the thick part was split again to accelerate drying.

The fish was sun dried again for a day.

Moisture, protein, fat and ash contents of raw material used were $79.26 \%, 19.06 \%, 0.31 \%$ and $1.30 \%$ respectively

\section{Boiled salted oil sardine}

Boiled salted oil sardine and its raw material were obtained from a processor in Muncar, East Java. The product was processed through the following procedures:

Oil sardine was washed and arranged on the bamboo package.

- The package containing the fish was boiled in salt solution for 25 minutes and then dripped.

- Warm salt solution was sprayed on the surface of the fish and after that fine salt was sprinkled over the surface of the fish. Finally, allow the fish to cool.

Proximate composition of raw material used was $62.36 \%$ moisture, $14.54 \%$ protein, $21.39 \%$ fat and $1.39 \%$ ash.

\section{Canned oil sardine}

Canned oil sardine samples were purchased from processors in Muncar, East Java. Raw material arriving in the factories in fresh condition was chilled in a concrete tank with a mixture of ice and salt. The canned fish product was processed using the following methods:

- Head, tail and visceral parts were removed and then washed using clean water.

The fish were packed in can and precooked using steam at $60-100^{\circ} \mathrm{C}$ for $5-10$ minutes.
- The released water was discarded and tomato sauce was added by leaving $10 \%$ head space.

The cans were sealed, washed and then sterilized at $116-120^{\circ} \mathrm{C}$ for 90 minutes.

The sterilized canned fish was quickly immersed into cool water.

Moisture, protein, fat and ash contents of raw material used were $61.40 \%, 12.46 \%, 24.90 \%$ and $1.30 \%$ respectively.

\section{Storage Study}

Storage study was conducted for dried salted short-bodied mackerel, boiled salted oil sardine and spongy fermented fish products. Storage was carried out at ambient temperature.

\section{Analyses}

Analyses were performed chemically and organoleptically to raw materials, fresh and deteriorated products. Raw materials were analyzed for proximate composition. Chemical analyses carried out during processing and storage were moisture content (AOAC, 1984), iodine value (Windsor \& Barlow, 1981), peroxide value (Windsor $\&$ Barlow, 1981), thiobarbituric acid (TBA) value (Lemon, 1975) and acetic acid soluble colour absorbance value (Anonimous, - - as well as fatty acid profiles. Bligh and Dyer method (Hanson \& Olley, 1963) was applied to extract fish lipid which will be used for the determination of iodine and peroxide values as well as fatty acid profiles. Methyl esters were prepared based on the method of the British Standard of Analysis of Fats and Fatty Oils (1980) with slight modification as described by Sunarya (1987). Fatty acid profiles were determined using HP Chromatography Model 437-A equiped with FID detector and chromosorb WAW sp-2330 column (100-200 mesh, 6 feet length and $2 \mathrm{~mm}$ ID). The carrier gas was nitrogen. The detector was kept at $230^{\circ} \mathrm{C}$ and the injection port at $230^{\circ} \mathrm{C}$. The column temperature was programmed from $180^{\circ} \mathrm{C}$ to $230^{\circ} \mathrm{C}$ with $5^{\circ} \mathrm{C}$ per minute rise and held at the upper temperature for 20 minutes. Organoleptic evaluation was used to determine the rejection points for each product.

\section{RESULTS AND DISCUSSION}

\section{Dried Salted Short Bodied Mackerel}

Fresh dried salted short bodied mackerel was absent from mould, pink bacteria and insect infestation. Meanwhile, the physical properties of the product were bright and firm as well as absent from physical damage and discolouration. The product became unacceptable to panellists after one 
Table 1. Results of proximate and other chemical analyses of dried salted short bodied mackerel

\begin{tabular}{lccc}
\hline \multirow{2}{*}{ Analyses } & \multirow{2}{c}{$\begin{array}{c}\text { Raw } \\
\text { Material }\end{array}$} & \multicolumn{2}{c}{$\begin{array}{c}\text { Dried Salted Short } \\
\text { Bodied Mackerel }\end{array}$} \\
\cline { 3 - 5 } & & Fresh & Rejected \\
\hline Moisture (\%) & 67.36 & 45.32 & 44.22 \\
Iodine value (g Iodine/100 g dry sample) & 232.14 & 134.25 & 131.34 \\
Peroxide value (meq/kg dry sample) & 130.55 & 128.16 & 31.62 \\
TBA value (mgMA/kg dry sample) & 6.37 & 1.13 & 5.54 \\
Acetic acid soluble colour (abs. unit/g dry sample/mL) & 32.17 & 14.26 & 57.91 \\
\hline
\end{tabular}

month storage as getting dull and brownish. Besides, rancid odour was detected.

Processing of dried salted fish obviously reduced iodine value of fish. However, the iodine value of dried salted fish product was insignificantly affected by storage treatment. The reduction of iodine value was probably mainly due to oxidation reaction attacking unsaturated fatty acids, particularly during drying process. This indication was supported by the results of peroxide value analyses.

Peroxide value of fish insignificantly changed during processing. On the contrary, storage treatment resulted in peroxide value reduction. This reduction might be due to the conversion of hydroperoxide into the secondary products of oxidation. This fact was supported by the results of TBA value analyses, in which the TBA value of

Table 2. Results of fatty acid profile analyses of dried salted short bodied mackerel (\% fatty acids)

\begin{tabular}{|c|c|c|c|}
\hline \multirow{2}{*}{ Analyses } & \multirow{2}{*}{ Material } & \multicolumn{2}{|c|}{$\begin{array}{c}\text { Dried Salted Short } \\
\text { Bodied Mackerel }\end{array}$} \\
\hline & & Fresh & Rejected \\
\hline C14:0 & 8.0 & 11.1 & 6.6 \\
\hline C16:0 & 31.2 & 45.7 & 48.8 \\
\hline $\mathrm{C} 16: 1$ & 8.4 & 10.8 & 7.8 \\
\hline C18:0 & 13.6 & 10.7 & 15.3 \\
\hline C18:1 & 11.7 & 13.3 & 14.1 \\
\hline C18:2 & & - & - \\
\hline C20: 1 & 2.3 & 2.1 & 1.5 \\
\hline $\mathrm{C} 22: 1$ & 1.4 & - & - \\
\hline EPA & 8.0 & 2.0 & 1.6 \\
\hline DHA & 15.6 & 4.3 & 4.2 \\
\hline SAFA & 52.7 & 67.5 & 70.7 \\
\hline MUFA & 23.7 & 26.2 & 23.4 \\
\hline PUFA & 23.6 & 6.3 & 5.8 \\
\hline
\end{tabular}

dried salted short bodied mackerel increased during storage. However, the TBA value of fish reduced as results of drying treatment. The TBA value of dried salted fish before storage was lower than the value in raw material.

Acetic acid soluble colour absorbance value of raw material was higher than that of dried salted fish. These results reflected that the colour of fish flesh became lighter due to drying process. Carotenoids constitute the most common pigments in fish (Brody, 1965). The decomposition of carotenoids induced by atmospheric oxygen would result in loss of colour and form a more weakly coloured product (Emodi, 1978; Clydesdale \& Francis, 1976) as found in this study. On the other hand, storage treatment caused the colour of fish flesh of dried salted product darker which was shown by the increase of absorbance value. Lipid oxidation and browning reactions may have resulted in that darker colour.

The relative amount of polyunsaturated fatty acids in short bodied mackerel decreased sharply when processed into dried salted products. Sharp decrease was also found for EPA and DHA. This result indicates that salting and drying through oxidation process could induce a severe effect on polyunsaturated fatty acids, especially EPA and DHA. Those changes were significantly detected by iodine value analyses. Storage of that product resulted in a little change to saturated and monounsaturated fatty acids, while EPA, DHA and polyunsaturated acids were relatively constant. 
Table 3. Results of proximate and other chemical analyses of spongy fermented fish

\begin{tabular}{lccc}
\hline \multirow{2}{*}{ Analyses } & \multirow{2}{*}{\begin{tabular}{c} 
Raw \\
\cline { 4 - 5 }
\end{tabular}} & Saterial & Spongy Fermented Fish \\
\cline { 4 - 5 } & 79.26 & 45.21 & Rejected \\
\hline Moisture (\%) & 334.28 & 120.90 & 42.74 \\
Iodine value (g Iodine/100 g dry sample) & 305.79 & not detected & 20.82 \\
Peroxide value (meq/kg dry sample) & not detected & not detected & not detected \\
TBA value (mgMA/kg dry sample) & 4.63 & 2.46 & 4.45 \\
\hline Acetic acid soluble colour (abs. unit/g dry sample/mL) & & &
\end{tabular}

\section{Spongy Fermented Fish}

Spongy fermented fish product used in this study was classified as the best quality according to the processor. Organoleptic properties of this fresh spongy fermented fish was slightly dirty and dull, yellowish white, delicious and specific fermented odour and taste, firm, elastic and absent from mould and colouring bacteria. After one month storage, panellists disliked the product due to spoilage odour and dark brown colour. Insect infestation was very obvious in this product.

Processing induced a sharp decrease in iodine value of fish. However, the iodine value of spongy fermented fish slightly decreased during one month storage. This result showed that processing has brought about the reduction of the number of unsaturated fatty acid portions within triglycerides. This reduction could be resulted from the oxidation process.

Table 4. Results of fatty acid profile analyses of spongy fermented fish ( $\%$ fatty acids)

\begin{tabular}{cccc}
\hline & \multirow{3}{*}{$\begin{array}{c}\text { Raw } \\
\text { Analyses }\end{array}$} & \multicolumn{2}{c}{$\begin{array}{c}\text { Spongy Fermented } \\
\text { Material }\end{array}$} \\
\cline { 3 - 4 } & & Fresh & Rejected \\
\hline C14:0 & - & - & - \\
C16:0 & 27.4 & 19.7 & 33.1 \\
C16: 1 & - & - & 9.3 \\
C18:0 & 12.9 & 21.4 & 15.5 \\
C18: 1 & 25.2 & 23.2 & 25.0 \\
C18:2 & - & - & - \\
C20:1 & - & - & - \\
C22: 1 & - & - & - \\
EPA & 12.9 & 15.8 & 7.5 \\
DHA & 21.6 & 20.0 & 9.6 \\
SAFA & 40.3 & 41.1 & 49.6 \\
MUFA & 25.2 & 23.2 & 34.3 \\
PUFA & 34.5 & 35.8 & 17.1 \\
\hline
\end{tabular}

Hydroperoxide was not detected in the fresh spongy fermented fish and this indicated that processing could pronouncedly decreased the peroxide value of marine catfish. However, storage resulted in the increase of peroxide value and this occurrence was a common phenomenon in oxidation reaction as also noted by Hawrysh et al. (1989) in canola oil. Hydroperoxide is readily to decompose into secondary product of oxidation. Formation and decomposition rates of hydroperoxide affect peroxide values of the product. Increase of peroxide value may be due to the higher formation rate of hydroperoxide than its decomposition rate and vice versa.

TBA value analysis exhibited that malonaldehide was not detected in both raw material and spongy fermented fish product. This result indicated that most malonaldehide might react with amino acids, peptides and other food constituents to form products in which malonaldehyde exists in bound form (Kwon et al., 1965).

Absorbance value of acetic acid soluble colour of marine catfish decreased during processing, but storage treatment of spongy fermented fish product resulted in the increase of that value. This means that the colour of the flesh from rejected product was darker than the fresh one. Oxidation and browning reaction may have encouraged colour changes.

Processing of spongy fermented fish did not show any significant effect on the relative amounts of saturated and polyunsaturated fatty acids. Meanwhile, this processing practice slightly decreased the proportion of monounsaturated fatty acids. In terms of polyunsaturated fatty acids, DHA was relatively constant, but EPA slightly increased.

Storage indicated a significant effect on the fatty acid profile of spongy fermented fish. Polyunsaturated fatty acids was severely affected by storage treatment, particularly EPA and DHA. This revealed that oxidation process intensively 
attacked polyunsaturated fatty acids during storage. However, the relative amounts of saturated and monounsaturated fatty acids increased as the compensation of polyunsaturated fatty acid decrease.

\section{Boiled Salted Fish}

Fresh boiled salted oil sardine showed properties as follows: interesting appearance, delicious and fresh specific boiled salted fish odour and taste, firm, and absent from both physical damage and mucous. Meanwhile, most panellists liked the product very much. Boiled salted fish was unacceptable for consumption after 5 days of storage. At that time, the product was slimy and had spoilage odour and taste, slightly dirty appearance, and fragile texture.

Processing of boiled salted fish yielded significant reduction in iodine value of oil sardine. This exhibited that the boiling treatment generated destruction of unsaturated fatty acids in triglycerides, particularly through oxidation reaction. Boiling was carried out at high temperature in an uncovered container using brine solution which may contain impurities acting as pro-oxidants. Those factors may have encouraged oxidation reaction. However, iodine value of boiled salted fish was insignificantly affected by storage treatment.

Peroxide value of fish increased as a result of the processing. Storage also brought about the increase of peroxide value of boiled salted fish. TBA content of oil sardine also increased due to the processing, but then decreased during the storage of the product. Similar pattern was also noted by Nair et al. (1979). This decrease could be due to the reaction between malonaldehide with amino acids, peptides and other food constituents (Kwon et al., 1965). Malonaldehyde can cross link protein through a Schiff base reaction with the e- $\mathrm{NH}_{2}$ group of lysine (Belitz \&

Table 5. Results of proximate and other chemical analyses of boiled salted fish

\begin{tabular}{lccc}
\hline \multirow{2}{*}{\multicolumn{1}{c}{ Analyses }} & Raw & \multicolumn{2}{c}{ Boiled Salted Fish } \\
\cline { 3 - 4 } & Material & Fresh & Rejected \\
\hline Moisture (\%) & 62.36 & 60.38 & 59.28 \\
Iodine value (g Iodine/100 g dry sample) & 198.80 & 158.20 & 156.68 \\
Peroxide value (meq/kg dry sample) & 150.98 & 198.01 & 255.98 \\
TBA value (mgMA/kg dry sample) & 3.64 & 10.47 & 6.58 \\
Acetic acid soluble colour (abs.unit/g dry sample/mL & 36.03 & 40.00 & 33.30 \\
\hline
\end{tabular}

Table 6. Results of fatty acid profile analyses of boiled salted fish (\% fatty acids)

\begin{tabular}{cccc}
\hline & \multirow{2}{*}{$\begin{array}{c}\text { Raw } \\
\text { Analyses }\end{array}$} & \multicolumn{2}{c}{ Boiled Salted Fish } \\
\cline { 3 - 4 } & Material & Fresh & Rejected \\
\hline C14:0 & 11.2 & 10.7 & 12.2 \\
C16:0 & 25.0 & 27.9 & 35.2 \\
C16: 1 & 9.9 & 9.8 & 11.5 \\
C18:0 & 3.9 & 4.4 & 6.0 \\
C18: 1 & 9.9 & 11.7 & 13.6 \\
C18:2 & 1.4 & 1.3 & - \\
C20:1 & 9.2 & 11.0 & 6.9 \\
C22:1 & 1.4 & 1.5 & - \\
EPA & 12.3 & 9.4 & 11.9 \\
DHA & 16.1 & 12.5 & 3.0 \\
SAFA & 40.1 & 42.9 & 53.3 \\
MUFA & 30.3 & 29.0 & 31.9 \\
PUFA & 29.7 & 23.2 & 14.9 \\
\hline
\end{tabular}

Grosch, 1987; Gilliat et al., 1988). Malonaldehyde can also undergo aldol-type reactions to produce a mixture of polymers (O'Brien, 1987).

Absorbance value of acetic acid soluble colour value of oil sardine processed into boiled salted fish product increased. This result indicated that processing method employed by proceesors produced darker colour of fish flesh. However, the value decreased when boiled salted fish product was stored until rejected by the panellists. Complex reactions, such as carotenoid destruction, lipid oxidation and browning reaction, may have induced these colour changes. If lipid oxidation and browning reaction rates were higher than carotenoid destruction rate, the colour would be darker and vice versa.

Polyunsaturated fatty acids proportion in oil sardine significantly reduced due to the processing of boiled salted fish and this was clearly shown by the decrease of EPA and DHA (Table 6.). However, monounsaturated and saturated fatty 
acids slightly decreased. Five day storage at ambient temperature caused a significant decrease of polyunsaturated fatty acids proportion, especially DHA.

\section{Canned Fish}

Canning process encouraged the reduction of iodine value of fish during canning process. This indicate that canning caused deterioration of unsaturated fatty acids within triglycerides. However, canning process resulted in a significant decrease in peroxide value. During sterilization, hydroperoxide might undergo a variety of scission and dismutation reactions to form a wide spectrum of carbonyl compounds, hydroxy compounds, short chain fatty acids, dimers and polymers (Smouse, 1978). TBA value showed insignificant change during canning process

Canning process through oxidation reaction markedly reduced the relative amount of value. Meanwhile, this process did not obviously affect the relative amount of monounsaturated fatty acids.

\section{CONCLUSIONS}

In terms of fatty acid profiles, oxidation occurred during processing of dried salted fish, boiled salted fish and canned fish significantly reduced the relative amount of polyunsaturated fatty acids, but the reduction of those acids were not obviously shown during processing of spongy fermented fish. Iodine value decrease due to the processing treatment was observed in all products under investigation.

Storage study revealed that dried salted short bodied mackerel, boiled salted oil sardine and spongy fermented marine catfish should not be stored more than 1 month, 5 days and 1 month respectively. Oxidation process during storage did not influence the relative amount of

Table 7. Results of proximate and other chemical analyses of canned fish

\begin{tabular}{lcc}
\hline \multicolumn{1}{c}{ Analyses } & Raw Material & Canned Fish Product \\
\hline Moisture (\%) & 62.36 & 67.82 \\
Iodine value (g Iodine/100 g dry sample) & 198.80 & 160.84 \\
Peroxide value (meq/kg dry sample) & 150.98 & 24.74 \\
TBA value (mgMA/kg dry sample) & 3.64 & 4.04 \\
\hline
\end{tabular}

polyunsaturated fatty acids. The decrease of polyunsaturated fatty acids was particularly shown by DHA having six double bonds. This results was supported by the decrease of iodine

Table 8. Results of fatty acid profile analyses of canned fish (\% fatty acids)

\begin{tabular}{ccc}
\hline Analyses & Raw Material & Canned Fish Product \\
\hline C14:0 & 11.2 & 13.1 \\
C16:0 & 25.0 & 32.1 \\
C16: 1 & 9.9 & 13.8 \\
C18:0 & 3.9 & 5.6 \\
C18: 1 & 9.9 & 11.9 \\
C18: 2 & 1.4 & - \\
C20: 1 & 9.2 & 5.1 \\
C22: 1 & 1.4 & - \\
EPA & 12.3 & 10.4 \\
DHA & 16.1 & 8.1 \\
SAFA & 40.1 & 50.8 \\
MUFA & 30.3 & 30.7 \\
PUFA & 29.7 & 18.5 \\
\hline
\end{tabular}

polyunsaturated fatty acids in dried salted fish, but significant effect was noted in spongy fermented fish and boiled salted fish.

\section{ACKNOWLEDGEMENTS}

Financial support for this study was provided by the European Commission through STD-3 Project (Contract TS3*CT93-0207): 1994-1997

\section{REFERENCES}

Anonymous, - Acetic Acid Soluble Colour (hand out). School of Food Studies-Humberside College of Higher Education, Grimsby, UK. 2 pp

AOAC, 1984. Official Methods of the Association of Official Analytical Chemists. $14^{\text {th }}$ edition. AOAC, Virginia, USA. $1141 \mathrm{pp}$.

Belitz, H.D. and Grosch, W. 1987. Food Chemistry. Springer-verlag, Berlin, Germany. 774 pp.

Brody, J. 1965. Fishery By-products Technology. The AVI Publishing Co. Ltd, Westport, Connecticut, USA. 232 pp.

Clydesdale, F.M. and Francis, F.J. 1976. Pigments. In Fennema, O.R. (ed.). Food chemistry, Marcel Dekker Inc., New York, USA. p 385.426. 
Directorate General of Fisheries. 1998. Fisheries Statistics 1996. Ministry of Agriculture, Jakarta, Indonesia. $73 \mathrm{pp}$

Emodi, A., 1978. Carotenoids, properties and applications. Food Technol. 32(5): 38-48.

Gilliat, P.N., Kochhar, S.P., and Rossell, J.B. 1988. A survey of the literature on the interaction of oxidised lipids with proteins No.163. Leatherhead Food RA, Surrey, UK. 47 pp.

Hanson, S.W.F. and Olley, J. 1963. Application of the Bligh and Dyer method lipid extraction to tissue homogenates. Biochem. d. 89: 101-102.

Hawrysh, Z.J., Shand, P.J., Tokarska, B. and Lin, C. 1989. Effects of tertiary butylhydroquinone on storage stability of canola oil. II. Practical storage. Can. Inst. Food. Sci. Technol. J. 22: 40-45.

Kwon, T., Menzel, D.B. and Olcott H.S. 1965. Reactivity of malonaldehyde with food constituent. J. Food Sci. 30: 808-813.

Lemon, D.W. 1975. An improved TBA test for rancidity. New Series Circular No.51. Halifax
Laboratory, Fisheries and Marine Service, Halifax, Nova Scotia, Canada. 2 pp.

Nair, P.G.V., Antony, P.D. and Gopakumar, K. 1979. Oxidative rancidity in the skin and musle lipids of oil sardine (Sardinella longiceps). J. Food. Sci Technol. 16: 151-154

O'Brien, P.J. 1987. Oxidation of lipids in biological membranes and intracellular consequences. In Chan, H.W.S. (ed.). Autoxidation of unsaturated lipids. Academic Press, London, UK. p 233-280.

Smouse, T.H. 1978. Oil stability, In Peterson, M.S.P. and Johnson, A.H. (eds.). Encyclopaedia of Food Science. The AVI Publishing Co.Inc., Westport, Connecticut, USA. p 577-580.

Sunarya, 1987. Extraction and Storage Stability of Nutritionally Important Components of Shark Liver Oil. PhD Thesis, Humberside College of Higher Education, Humberside, UK. p 91-92.

Windsor, M. and Barlow, S. 1981. Introduction to Fishery By-products. Fishery News Books Ltd., Surrey, England. 187 pp. 